\title{
Application of Ninivite Silica Rocks as a desiccant material in cooling systems
}

\author{
R. A. Buker \\ Department of Chemistry \\ College of Education \\ University of Mosul
}

Received

02 / 08 / 2011

\author{
B. M. A Al-Ali O. M. Hamdoon \\ Department of Mechanical Eng. \\ College of Engineering \\ University of Mosul
}

الملخص

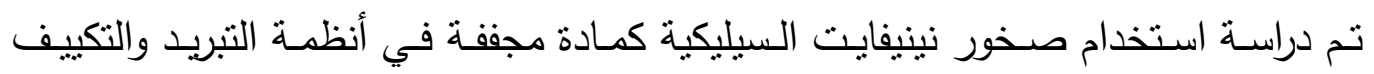

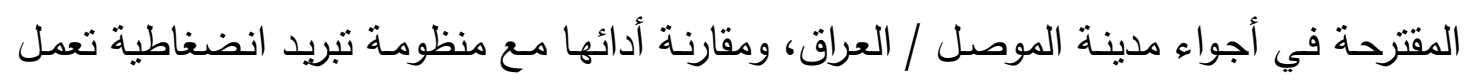

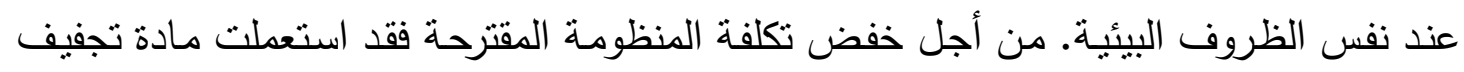

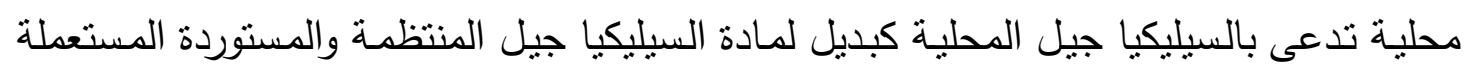

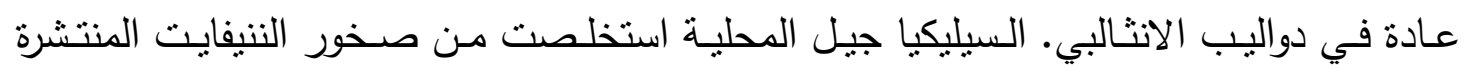
جنوب مدينة الموصل / العراق وقد تم إيجاد بعض الخواص الفيزيائية والحرارية لهذه المادة عملياً ومن ثم مقارنتها بخواص السيليكيا جيل المنتظمة المستوردة.

\begin{abstract}
The performance of a proposed air conditioning system under the weather of Mosul city / Iraq has been studied and compared with that of the vapour compression system operating at the same condition. For the purpose of reducing the cost of the proposed system, a local desiccant material called local silica gel was used as an alternative to the regular density silica gel which is usually used in the enthalpy wheels. This material was extracted from Ninivite rocks available at south of Mosul city / Iraq. Some of the Physical and thermal properties of this material were experimentally determined and compared with those of the regular density silica gel.
\end{abstract}

\section{Introduction}

The demand for electric power is increasing overall the world particularly during summer season when the demand for electric power 
reaches its peak ${ }^{(1)}$. Most certainly, quite high proportions of the generated power during summer will be used by building air conditioning systems. One of the most suggested solutions to the problem of peak load in buildings is reducing the electric power consumed by the air conditioning systems. Such systems are based on the idea of controlling the temperature and relative humidity of the conditioning space available. The use of desiccant cooling system insures the desiccation of the air before entering the vapour compression system and guarantees a reduction in the electric power consumption.

This process is usually done by inforsing the air through desiccant wheel ${ }^{(2)}$ where as the desiccant material. The most material used for this purpose is the regular density silica gel ${ }^{(3)}$ (RDSG), which characterized by the high ability to adsorb humidity from the air or releasing humidity to the air when it passes through the wheel as a result of the differences in the water vapour pressure between the air and the desiccant material. However, in our investigation the natural local silica gel (LSG) named Ninivite silica rocks ${ }^{(4)}$ will be used instead of RDSG. Fortunately, it was reported that silica gel occurrs naturally in large masses in our country. Numerous occurrences of silica - rich rocks named Ninivite ${ }^{(5)}$ have been described for the first time from the Miocene of northern Iraq, Figure (1). Ninivite silica rocks are considered of great industrial importance ${ }^{(6)}$ due to their a high silica content, low bulk density, and high porosity.

\section{Experimental}

Ninivite silica rocks, which are obtained from areas around Mosul city / Iraq, were used as a starting materials for the preparation of the local desiccant material sample following procedures reported recently ${ }^{(7)}$. The purified silica sample as well as the industrial one were studied using several chemical analysis methods to determine their chemical compositions ${ }^{(8)}$.

Moreover, physicochemical properties also were determined like density, porosity, water absorption capacity. And specific surface area, which was determined by ethylene glycol method ${ }^{(9)}$.

Testing the performance of the proposed system under the weather conditions of Mosul city / Iraq, was done with different designing and operating specifications. Such technical test was performed using the properties of the local desiccant material and the regular density industrial silica gel in weather of Mosul city in two cases, the ventilation and mixing mode.

\section{Results and discussion}

Chemical composition of Ninivite silica rocks existing south of Mosul city studied for the first time in $1989^{(5)}$. This study explained that the most important constituents of this rock with their percentage ratios 
were as follows: crystalline and amorphous silica (94.6\%), alunite $(0.7 \%)$, oxides $(1.03 \%)$ and sulfates $(0.3 \%)$. This rock was identified from its high porosity, surface area, capillary action, and adsorption capacity besides its low density, Table (1). The appearance of adsorption in these rocks is attributed to its containing of amorphous silica which is about $45 \%$.

It is obvious that the present study involves several stages in term of air conditioning system which include the enthalpy wheel. The aim of adding the enthalpy wheel is to dehumidify the air before passing through cooling coil to reduce the latent load. The total moisture removed from the supply air can be measured from the conditions of the air leaving the enthalpy wheel. Thus the task of the present model of the enthalpy wheel is to asses the conditions of the air coming out from wheel (humidity ratio and temperature). Figure (2) shows the transient humidity ratio profiles (humidity ratio with respect to time) using silica gel as desiccant material with a fraction of $(20 \%)$, the wheel rotates at normal rotational speed of 20 revolution per minute. It appears that a maximum change in humidity ratio value would be at the first point (the supplied air coming out from the wheel following its first cycle), due to the high effect of initial conditions in the first cycle. On the contrary, the supply air will get humidity from the saturated desiccant layer. This explains why the humidity ratio of the supply air leaving the enthalpy wheel following the first adsorption period is higher than the humidity ratio of the air entering the wheel. Figure (3) shows the relationship between the rotation speed at the enthalpy wheel and specific dehumidification power of both regular density silica gel wheel and local silica gel wheel. From this figure the similar behavior of the enthalpy wheel rotation speed in dehumidification effectiveness can be seen. An increase in the enthalpy wheel rotation speed leads to an increase in the specific dehumidification power, and maximum increase will be at low speeds.

Also it can be pointed out that the value the specific dehumidification power of the local silica gel is higher than that of the regular density silica gel, though dehumidification effectiveness of the latter is the highest. This can be attributed to the low density of the local silica gel $\left(\mathrm{pd}=490 \mathrm{Kg} / \mathrm{m}^{3}\right)$, compared to that of regular silica gel, which is $\left(\mathrm{pd}=720 \mathrm{Kg} / \mathrm{m}^{3}\right)$. Therefore, the local silica gel mass used in the enthalpy wheel will be much less than the regular silica gel mass at the same wheel sizes. For example, the desiccant material mass used in the local silica gel wheel is $17.36 \mathrm{~kg}$ compared to the $28.35 \mathrm{~kg}$ used in the regular one, if a desiccant layer thickness was kept constant in both cases at $0.3 \mathrm{~mm}$. since specific dehumidification value is a converse proportion with desiccant material mass, therefore the value of the specific dehumidification power in the local silica gel wheel will surpass that of the regular silica gel wheel. 
Finally, it would be useful to note here the effect of desiccant layer thickness on dehumidification efficient which is shown in figure (4). For example, an increase in the desiccant layer thickness from $0.1 \mathrm{~mm}$ to $0.2 \mathrm{~mm}$ will lead to an evident increase in surface area through changing the wheel size, and an increase in dehumidification effectiveness nearly by $1.57 \%$ with regular density silica gel wheel, and nearly by $3.16 \%$ with local silica one. Whereas, an increaser in the desiccant layer thickness from 0.5 to $0.6 \mathrm{~mm}$ lead to an increase of about $0.53 \%$ and 0.64 in dehumidification effectiveness respectively. These results agree with those achieved by Niu \& Zang ${ }^{(10)}$.

\section{Conclusion}

An air conditioning system suitable for dry and hot weather as that of Mosul city / Iraq has been suggested. This system contains enthalpy wheel as one of its constituents. The desiccant material used in the enthalpy wheel is a local silica gel, which is extracted from the Ninivite rock available south of Mosul city / Iraq. Physical properties of the local silica gel were experimentally found and compared with those of the regular density silica gel. These properties were used in the simulation of the proposed system which showed the accuracy of the suggested models.

\section{References}

1) Total world primary energy production and electricity consumption, U.S. report projects strong growth in world energy demand, 2006. www.pewclinate.org.

2) N. Subramanyam, M.D. Maiya, and S. Murthy, "Parametric studies on a desiccant assisted air conditioner", Applied Thermal Engineering, Vol. 24, P. 2679, 2004.

3) F. Kreeith, "Mechanical Engineering Handbook", Chapter 9, CRC press LLC.

4) S.Q., Al-Naqib, and T.H. Al-Dabbagh, "Some physical and geotechnical properties of the new rock type (Ninivite), "proc. of the $26^{\text {th }}$ annual U.k. / 9-13 Sep. 1990.

5) S.z Jassim, and S.Q. Al-Naqib, " Ninivite a new form of porcelanite minerals", j.Geo. Soc. Of Iraq, Vol. 22(1), P112, 1989.

6) R.A. Burker, and N.H Taher, Dirasat, 33B(2), P. 158, 2006.

7) R.A. Burker and A.S. Al-Botani, J. Ratidaine Sci., Vol. 20(2), P. 52, 2009.

8) K. Cornelis, "Mineral Sciences", $22^{\text {nd }}$ ed., John Wiley and Sons, New York, 2003.

9) K.A. Carrado, S.E. Yuchs, K. Song, and N. thiyagaraja, "Heterogeneous catalysts Based on clays", Perhaman press Ltd. Britian, 1996.

10) L.J. Niu, and L.Z. Zhang, Int. comm.., Heat Mass Transfer, vol. 29(2), P255, 2002. 
R. A. Buker \& B.M.A Al-Ali \& O.M. Hamdoon

Table (1): Physical properties of silica samples

\begin{tabular}{||l|c|c|c|c|c||}
\hline \multicolumn{1}{|c|}{ Sample } & $\begin{array}{c}\text { Density } \\
\mathbf{k g} / \mathbf{m}^{\mathbf{3}}\end{array}$ & $\begin{array}{c}\text { Porosity } \\
\mathbf{\%}\end{array}$ & $\begin{array}{c}\text { Water } \\
\text { absorption } \\
\mathbf{\%}\end{array}$ & $\begin{array}{c}\text { Surface } \\
\mathbf{a r e a} \\
\mathbf{m}^{\mathbf{2}} / \mathbf{g}\end{array}$ & $\begin{array}{c}\text { Specific } \\
\text { heat } \\
\mathbf{K J} / \mathbf{~ k g . k}\end{array}$ \\
\hline \hline Ninivite rocks & 712 & 45.8 & 61 & 765.7 & - \\
\hline Natural amorphous silica & 400 & 136 & 183.7 & 363 & 1090.71 \\
\hline Industrial silica gel & 500 & 114.5 & 233.6 & 830 & 921 \\
\hline
\end{tabular}

$43^{\circ} 00^{\circ} 00^{\circ}$

$43^{\circ} 17^{\prime} 30^{\circ}$

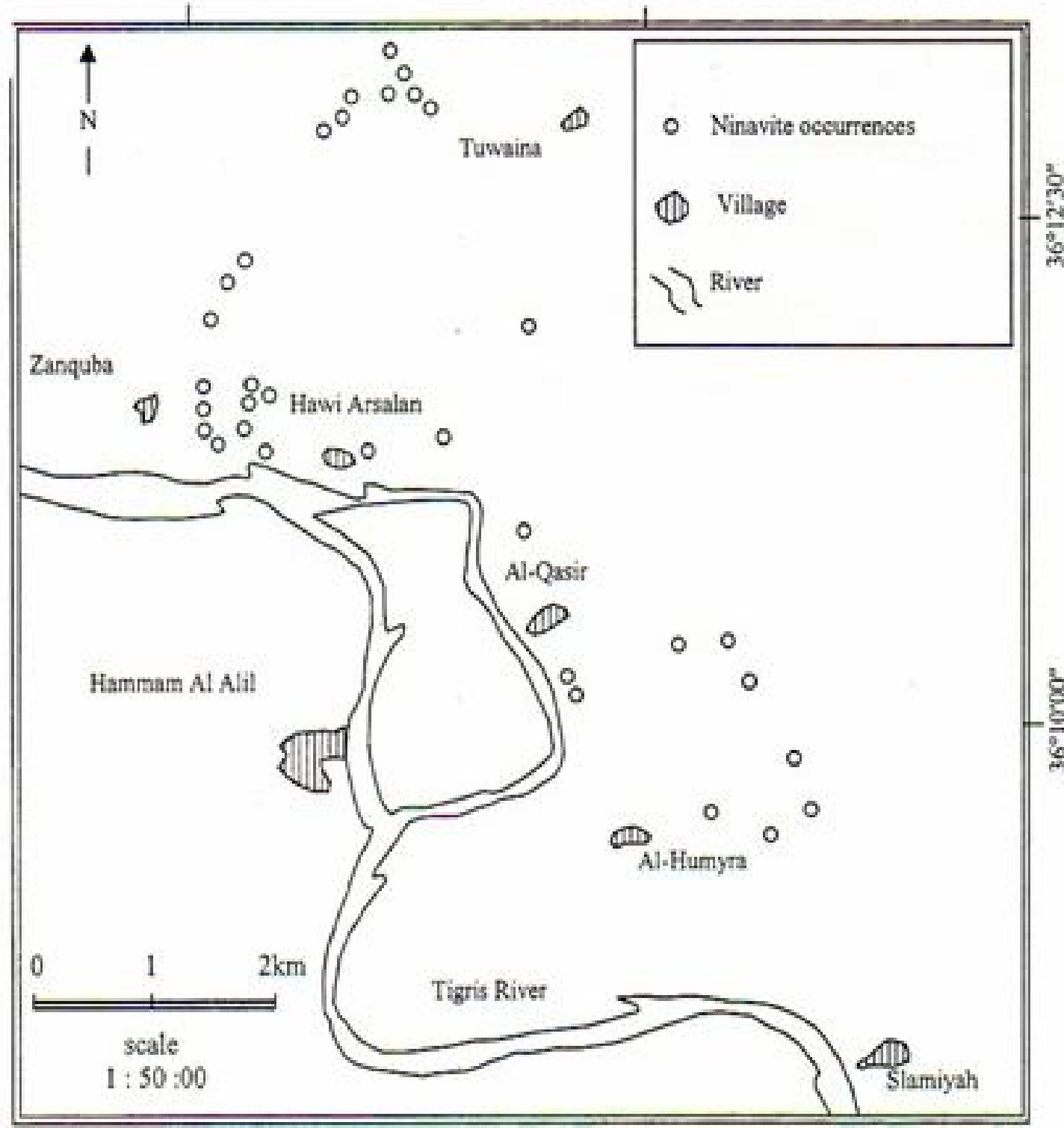

Figure ( 1 ): Ninavite rock locations. 
Application of Ninivite Silica Rocks as a desiccant material in cooling systems.

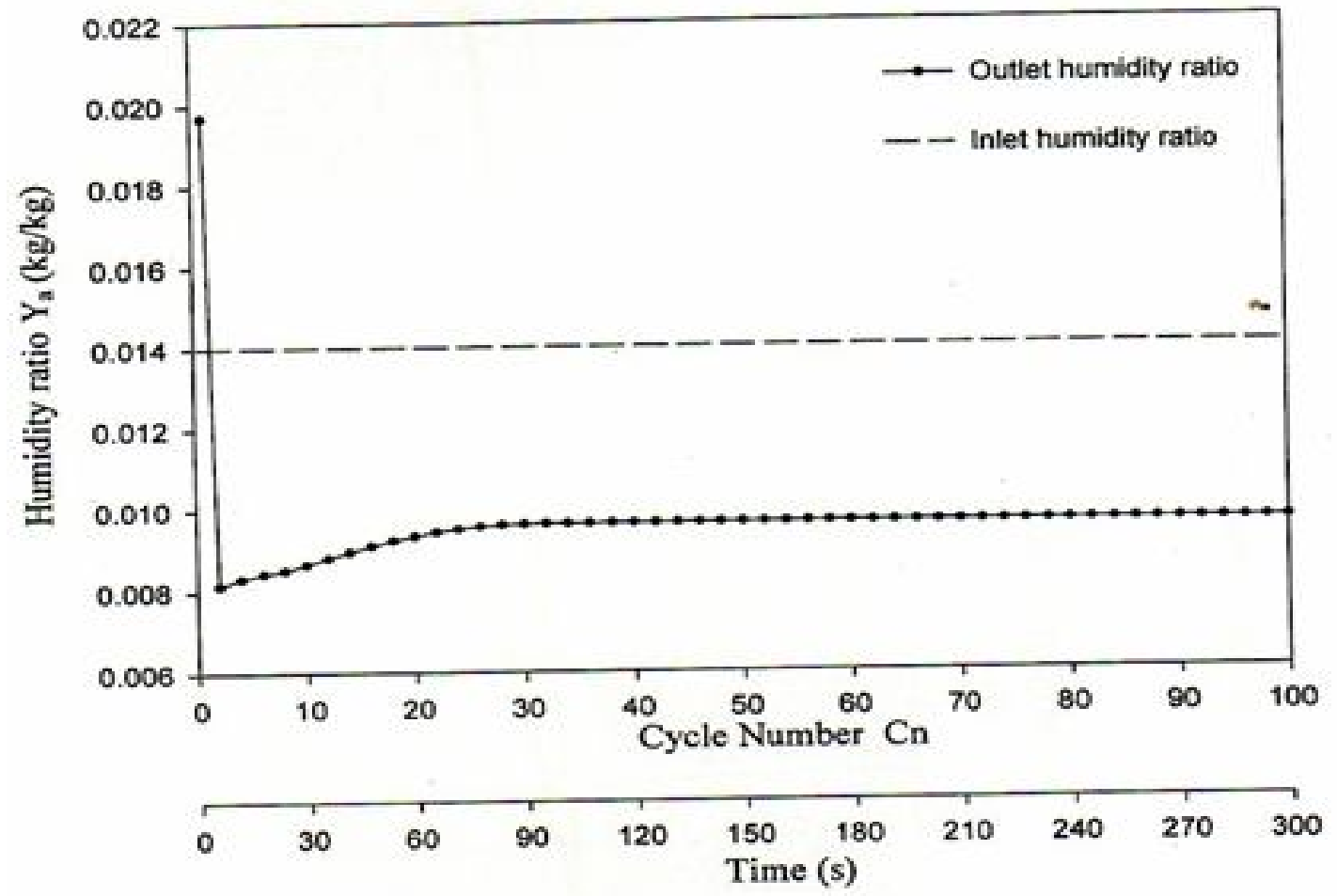

Figure (2): Variation of humidity ratio at the end of supply period every cycle.

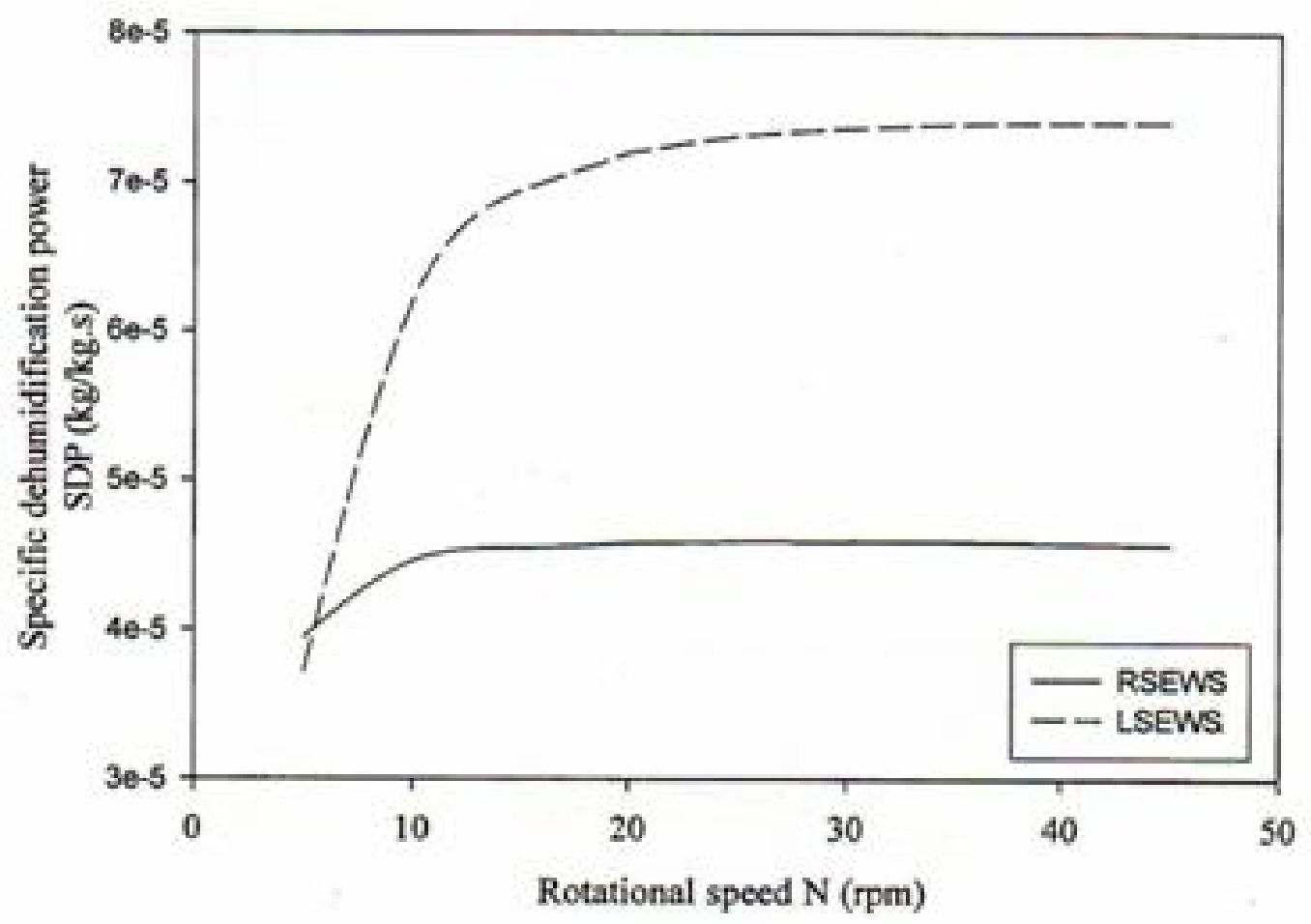

Figure ( 3 ): Effect of enthalpy wheel rotational speed on the specific dehumidification power. 
R. A. Buker \& B.M.A Al-Ali \& O.M. Hamdoon

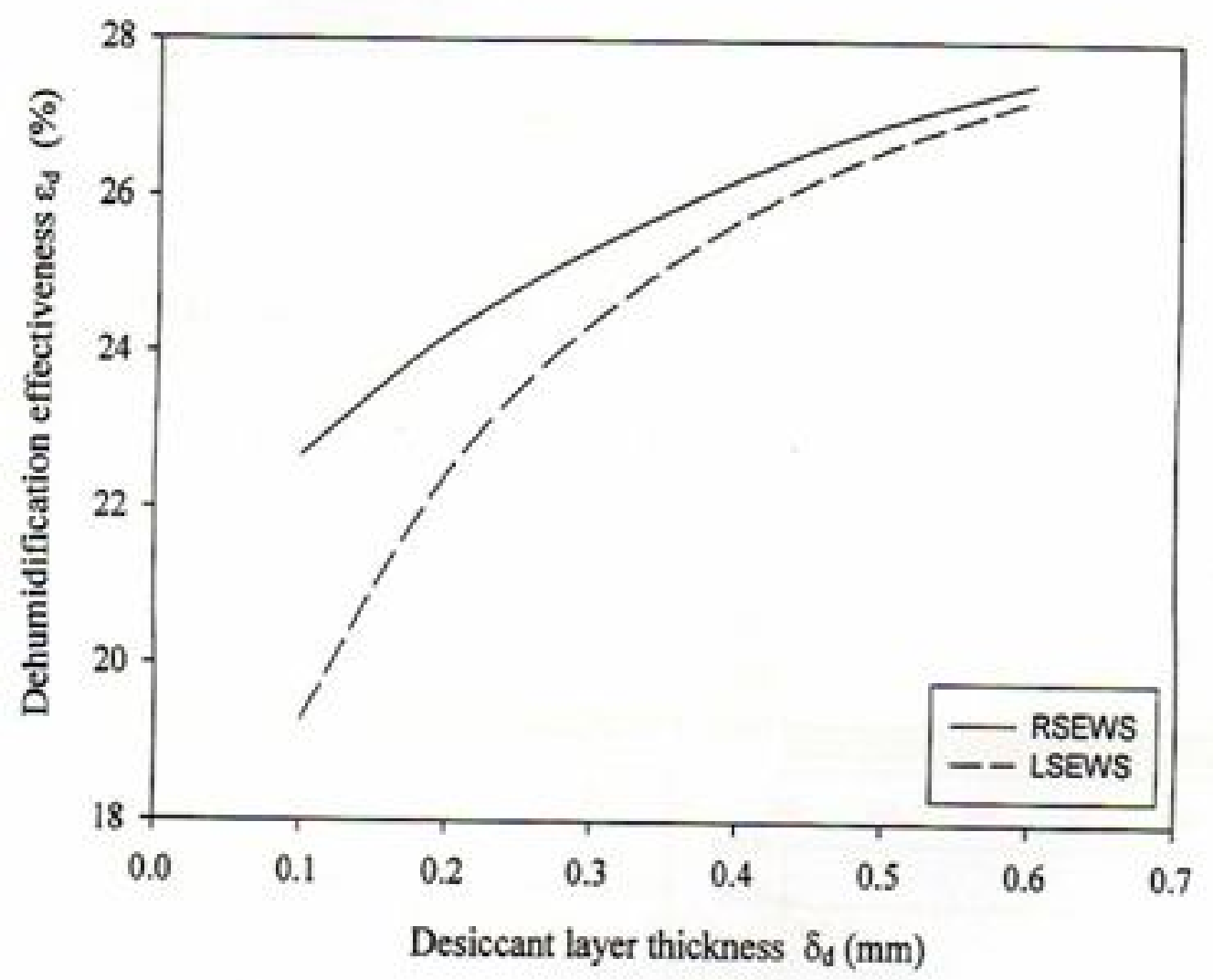

Figure ( 4 ): Effect of desiccant layer thickness on the dehumidification effectiveness. 